2011-06-01

\title{
Communities of praxis, scholarship and practice styles of the HE in FE professional
}

Gale, K::0000-0003-1296-9647

http://hdl.handle.net/10026.1/4294

\author{
10.1080/13636820.2011.572175 \\ Journal of Vocational Education and Training \\ Informa UK Limited
}

All content in PEARL is protected by copyright law. Author manuscripts are made available in accordance with publisher policies. Please cite only the published version using the details provided on the item record or document. In the absence of an open licence (e.g. Creative Commons), permissions for further reuse of content should be sought from the publisher or author. 


\section{Communities of Praxis? Scholarship and practice styles of the HE in FE professional}

The Dearing Report advocated that the traditionally separate post-compulsory education sectors of English higher education (HE) and further education (FE) should bring together the academic and vocational in a working partnership. This has led to significant changes in the working practices of colleges, lecturers and support staff. Drawing on the experiences of a sample of HE lecturers in colleges in south west England and a synthesis of relevant literature, this paper begins to examine the practice styles of HE lecturers working in FE institutions and the opportunities they are presented to engage with scholarship. The research acknowledges the issues involved in positioning $\mathrm{HE}$ in $\mathrm{FE}$ by considering the traditional roles of $\mathrm{FE}$ and $\mathrm{HE}$ lecturers, the competing demands of HE and FE and the necessary reconceptualisation of the HE in FE lecturer as a teacher, a researcher and a scholar.

Keywords: Higher Education, Further Education, Foundation Degrees, Professional Identity, Practice Styles, Scholarly Activity, Research.

\section{Introduction}

FE colleges have made a longstanding contribution to the provision of specialist vocational HE, primarily in the form Higher National Diploma (HNDs) / Certificates (HNCs) (Parry, 2009). They are viewed as playing a key role in widening participation and accessibility to individuals whose previous educational experiences preclude them from undertaking a traditional route through HE (DfES, 2003). However, the contribution made by FE colleges to HE is generally perceived as marginal, a construct that has resulted from successive educational policies that have maintained the boundaries between further and higher education (Parry, 2009; Scott, 2009). Indeed this perspective may have been reinforced by the growing social / cultural prejudice associated with HNCs / HNDs (DfES, 2003). There was also growing concern over the country's ability to compete in the global knowledge economy as well as meeting the needs of our own changing economy in the face of a predicated skills gap (DfES, 2003). The Dearing Report has sought to address these concerns and erode boundaries by charging colleges with a special mission to promote universal access to HE (NICHE, 1997). In taking forward Dearing's 
recommendations the government introduced foundation degrees (HEFCE, 2000). These were designed to bridge the academic-vocational divide that had built up through the traditional association of academic advancement/knowledge generation with universities and vocational training with colleges (Stanton, 2009). The renewed growth of $\mathrm{HE}$ in $\mathrm{FE}$ colleges lead to the establishment of what have become known as dual sector institutions (Bathmaker et al., 2008) where HE and FE are taught alongside one another. This dualism has immediate consequences for those with responsibility for enacting policies around $\mathrm{HE}$ in FE. There is an expectation for college lecturers to develop HE practice styles and undertake HE-related activities such as scholarly activity and research in an environment not traditionally associated with these activities (Anderson et al., 2003). Given this, there is a need to explore the ways in which the practice styles and scholarly activities of HE in FE lecturers are being conceptualised and contextualised. This paper considers the influence of institutional cultures, student profiles and partnership working on HE in FE lecturers and highlights the potential role of scholarly activity and research in enabling college lecturers to explore what some may consider a new professionalism.

\section{The Emergence of Communities of Praxis?}

As this research began to develop an awareness of the specific and highly situated nature of these emerging $\mathrm{HE}$ in FE contexts encouraged an analysis that draws in part on the work of Foucault (1980) and which focuses upon and adapts Lave and Wenger's (1991) germinal and highly influential work on 'communities of practice'. Adopting Lave and Wenger's community based approach to professional practice and with specific reference to research and scholarly activity within HE and FE, we also begin to address what Schön referred to as 'the crisis of confidence in professional knowledge' (1987: 3). In this respect the research was designed to shift the focus of investigation away from the rarified academic high ground of 'researchbased theory and technique' and into the 'swampy lowland (where) confusing problems defy technical solution' (ibid). Engaging in the research began to make it possible to envisage the HE in FE lecturer engaging with new and emerging issues to do with curriculum and practice within their subject area.

Awareness of such approaches suggested that this is likely to involve lecturers not only in dealing with the technocratic elements of course design and lesson planning 
but also in showing how such approaches constitute an act of scholarship in the discipline itself. In part this will also pay attention to the case made by Ball (1995) for the 'urgent role of theory' in education today. Therefore we have developed an argument based upon the evidence emerging out of the research that such an approach can be seen to involve managers, teachers and learners, in what we would tentatively term, the whole community of praxis, in justifying and explaining how $\mathrm{HE}$ in FE programmes of study not only operate in functional or utilitarian ways but also how they can be seen to represent the central theoretical and practical issues of a given discipline. In this way research and the scholarship of teaching and learning can afford reflexive opportunities for the community of praxis to engage in, not only, the intellectual and the vocational but also the affective and the ethical work of the subject as a whole.

As Lave and Wenger (1991) stress in their original conception, the highly situated nature of the community must always be taken into consideration and can often be recognised by what Bourdieu and Passeron (1977) referred to as it's habitus. In this research, colleges HE element also was found to vary considerably in size and importance and within this the role of individual members of staff is also diverse. Despite these apparent disparities and inconsistencies, theorising HE in FE communities of praxis also seemed to resonate with and build upon Boyer's (1990) innovative thinking on scholarship. In this respect evidence from the research enabled us to begin to focus upon the 'discovery' of emerging relationships between theory and research, upon the 'integration' across distributed disciplinary and institutional areas, upon the ways in which 'applications' of theory and research could be made, for example, in work based settings and upon 'teaching' practices that began to open up new theory practice translations. It also allowed us to consider Boyer's presentation of teachers as learners who transform and transmit knowledge.

Therefore and following the thinking of Lave and Wenger (1991) and Boyer (1990) the potential conflation of research and scholarly activity within the dynamic and changing context of HE in FE will necessarily involve professional practitioners within these newly forming communities of praxis in continually creating new concepts. We argue therefore this approach will also necessitate the continuing development of 
professional identities and practice styles that are prepared to flex and respond to the changes taking place within what Parry (2009) refers to as the FurtherHigher sector. Teaching and learning in this sense would be a lived practice of constant becoming, based upon risk taking and disidentification, offering disruption, challenges to the habitual, and invitations into the unknown.

\section{Researching HE in FE provision in south west England}

Since 1978 the University has been supporting HE through a dispersed network of partner colleges. This provision mirrors the cognate subject areas of the University (e.g. Arts \& Humanities / Education) and represents 13 colleges. Although these colleges generally offer small quantities of $\mathrm{HE}$ in relation to their FE provision, collectively the University's HE in FE is considerable, with 7,000 students registered on 300 courses delivered by 1,800 lecturing and support staff.

In the 2007-08 academic year a series of staff development activities were facilitated across the network. Using a purposeful sampling regime, college lecturers who had undertaken a specific staff development activity in four colleges, where investment in HE infrastructure had also taken place, were invited to participate (Bryman, 2008). The research team postulated that these individuals would have had sufficient time to consider the HE developments in their institutions, and therefore be able to conceptualise these changes in relation to their practice. All participants volunteered to participate, and subsequently, three lecturers from each college were selected to contribute to the research. The participants were all in teaching roles and had experience of FE. Six were involved in HE (e.g. HND/Cs) prior to the introduction of foundation degrees, and therefore had been involved in the development of these courses. They were selected to represent a cross-section of disciplines to ensure that subject specific issues did not exert an overriding influence on the findings.

Twelve semi-structured interviews were undertaken by a member of the research team unknown to the participants. This was to ensure the participants provided an holistic account of working in HE in FE, and not assume knowledge on the part of the researcher (Platt, 1981). The interviews explored their educational / professional backgrounds, perceptions of the role of HE lecturers working within universities, and how this compared and contrasted to the role they performed. Questioning also took 
place regarding the support available for them to undertake the role of a HE lecturer. The interviews were digitally recorded and transcribed in full. All identifying features were removed to ensure the anonymity of individuals and institutions involved. The transcripts were manually coded using the constant comparative approach; text being examined to identify comparisons and cross cutting themes (Glaser \& Strauss 1967).

\section{Professionalism and Practice style}

The traditional but probably somewhat idealised conception of the role of a university lecturer as a teacher is constructed as secondary to their role as researchers (Taylor 2008). Such a view presents a rather generalized picture in which the newly appointed academic is seen as entering $\mathrm{HE}$ teaching after a sustained period of concentrated study in which subject expertise and identity as a researcher within a chosen discipline is developed (Elton, 2001). This presents a somewhat traditionally pedagogic and cognitively based practice style designed to transmit and disseminate knowledge to passively recipient students. This is echoed by Ainley when he points out:

Indeed, if one visits a traditional university today, what is going on in most of the lecture and seminar rooms, let alone in the informal meetings of students on and off campus, is talking - not doing. The range of activities is generally very narrow: lectures in which one person talks to many; seminars or 'workshops' in which the numbers are reduced - in the case of tutorials to one to one.'

According to such a view the lecturer in HE is seen as being the 'expert', who possesses the subject knowledge and who, through the employment of teacher centered practices, 'delivers' the subject to the learner - a largely cognitivist or 'banking' model of education (Freire, 1972). In this guise, at best, the HE 'lecturer' can be seen to view it as their responsibility to promote a sense of inquiry and questioning within their students, and their own research is commonly used as a basis or a starting point for generating this (Healey, 2005). Ideally such a practice 
style would work to foster autonomy amongst students, encouraging them to take ownership of their learning.

However, over successive governments the increased level of intervention in educational policy, particularly within the lifelong learning sector, has challenged this view. Research by Ainley (1994), Clegg (2008), Nixon (1996) suggests that we are witnessing an emerging diversification in HE educational practices generally. Ball (1995) and Ecclestone (1999) have highlighted that there has been a gradual move away from risk taking and creativity toward a more restricted, reductionist and equally un-reflexive view of education. Indeed within HE Ainley observed:

Traditional subject boundaries are crumbling as the databases of previously discrete subject boundaries are interrelated by the new technology as well as the latest scientific discoveries. Professors and lecturers fearful of losing their formerly specialised knowledge or expertise are recast as the 'facilitators' of their students' independent learning. They face losing their students' former dependence upon them and see themselves relegated to the role of technicians or auxiliaries'

(1994: 30)

Presentations of the FE educational experience can be seen as functional and instrumental, framing teaching as a skill, rather than as an inspirational vocation or style of life (Shain \& Gleeson, 1999; Spenceley, 2006). Some (e.g. Parry, 2005) have argued that the gradual shift toward this technicist view of FE teaching has grown out of the sector being repeatedly used as a policy lever to respond to economic and training demands identified by government and which are acted upon locally by college lecturers on the ground. Policy developments targeted at the FE sector have placed a greater emphasis on outcomes related learning and evidence based practice; these appear to instrumentalise the relationship between teaching and learning (Spenceley, 2006). Hence the effectiveness of teaching is measurable through the successful completion of (learning) outcomes and students attaining predetermined 'competences' imposed externally. (Ball, 1995; Ecclestone, 1999). There is an emphasis on teaching quality which is monitored through systems of (performance) appraisal and periodic inspections (Humphries and Hoque 2007). 
With these 'benchmarks' becoming more and more discursively embedded 'quality assurance' becomes framed in terms of efficiency, as a technical issue of how well teachers practice and the technologies that 'manage' these practices gain credibility through their apparent neutrality and impartiality (Ecclestone, 1999). According to such a view, within the FE sector, teaching then is seen as a technical effort or skill which is underpinned by specific subject knowledge (Spenceley, 2006).

Respondents in this research suggests that there is a danger, therefore, that the professional identity of the HE in FE lecturer can become subsumed and congealed within the dominant policies, norms and values of the FE institutional culture.

HE and FE can be said to operate under contrasting cultural, organisational and institutional values which have implications upon the emerging practice styles. This is demonstrated by Respondent 1 who considers their desire to explore further subject specialism in line with envisaged HE practices:

Probably in my time here I have actually probably taught 14 totally different subjects which makes it hard for me to perhaps be an absolute specialist... whereas [at a university] I suspect you focus on one particular subject and teach that very, very well. Whereas we don't have the time, or resources or staffing for that to occur.

The constraints this Respondent experienced suggested an awareness of operating within a "generalist" mode which, whilst being acceptable for an FE professional practice style was not conceived as being consistent with or acceptable to HE modes of practice.. Indeed, not only does this suggest that the HE in FE lecturers were generalists in terms of the broad subject knowledge required for their teaching, but that they were also generalists in the requirements of their teaching practices. In the words of Respondent 4:

I teach all IT across those programmes, all professional development, study skills all that kind of thing. Also [...] research, statistics, project management...so I teach, I personal tutor and I spend a lot of my time on employer engagement.. 
Indeed for many respondents the generalist tendencies appeared to be reinforced by their colleges' approach to the management of HE. As suggested by Respondent 6, no specific training, support or advice is given to HE in FE lecturers to assist them in developing their HE practice styles, rather this appeared to be determined on the basis of on an individual's own judgment:

I don't think the college has ever made me aware of what a HE practitioner's role is. I personally don't feel, because I teach FE and HE [...] I don't really think that distinction has ever been communicated to me; you just sort of pick it up and get absorbed into it.

Other respondents felt that their colleges' systems for quality assurance, which they viewed as been geared toward $\mathrm{FE}$, were inappropriate and undermined the practice styles they were employing with their HE students:

Well interestingly at the moment as far as inspections are concerned, inspections of my class, is that we seem to be inspected under an OFSTED banner and it causes a bit of concern for us because if we decide that the lesson means that students are away doing some research, and then the inspector turns up and there is an empty room then you get some bad marks." (Respondent 3)

The lack of obvious recognition for HE practice styles and the pervasiveness of the FE institutional culture was acknowledged by all the respondents, however for some it was not only the approach taken by the college that constrained the development of their emerging practice styles. The facilities they were working with were often shared spaces with the college's FE provision and therefore, whilst there may be dedicated HE social spaces, dedicated HE learning spaces were often limited due to the disparate nature of many colleges' HE provision:

...we are a relatively small provision in the area; I think nearly all the $H E$ provision in the college is very much in isolation because we are a relatively small part of a large organisation. And I expect part [of] the reason why we 
aren't taken terribly seriously because we're a few and they [FE] are a lot. Respondent 2

Consequently the majority of respondents felt that they were not in a position to ask for a greater level of recognition, professionally or contractually, when HE represented only a minority of their college's overall provision:

But I think with such a low mass of students, I don't think that until the mass increases I don't actually think we're going to have a voice big enough to be able to change that." Respondent 12

Although HEFCE (2003; 2009) acknowledged that HE within FE college will be in the minority, this provided little consolation for the respondents, who, despite support from their partner university, experienced a sense of isolation and felt that they were not visibly part of a wider community of $\mathrm{HE}$.

\section{Scholarly Activity and Research}

As highlighted at the beginning of this paper, the expansion of HE into FE had placed a greater emphasis on college lecturers to be provided with opportunities to engage with scholarly activity and research. Indeed, Parry and Thompson (2002) indicated that college lecturers were in a "unique" position to further research into HE in FE, which has been acknowledged as an area commonly overlooked by the research community. However, this does not mean that FE colleges represent an environment devoid of research; rather the focus on learning and teaching has meant that research does not hold the same currency as in universities (Child, 2009). In contrast to a university setting, whereby a lecturer's professional creditability is measured by an individual's research output and grant income, in an FE college a lecturer's professional progression is determined by the attainment and achievement of their students and successful Ofsted inspection (Child, 2009; Elton, 2001). These contrasting positions were acknowledged by participants in this research: 
"Because I think we are both following our traditional models [...] and the point of universities is to develop ideas then develop the thinking behind those ideas so develop their ideas through research and then develop the students to go along with that. We come from teaching 16 year olds and you have to tell them how to do things and you have to teach them skills." Respondent 9

Although there are examples where research has been supported/taken place within FE colleges, either independently (e.g. Cunningham \& Doncaster, 2002) or in partnership with a universities (e.g. the Transforming Learning Cultures in Further Education, an ESRC-TLRP led by four universities in association with a network of FE colleges) these are generally few and far between. Therefore whilst HEFCE (2003) called for college lecturers to be provided with opportunities for scholarly activity and research, given that this is not necessarily an accepted part of a lecturers day to day role, for many engaging in scholarly activity and research has proved challenging:

"So I think it's a very difficult one and I know that the HE lecturers, particularly the programme managers who I talk to are extremely frustrated that no value is given to kind of getting higher degrees and doing research. It's not seen as important yet it is written in the contract as part of your role." Respondent 5

The introduction in 2009 of the Continuing Professional Development (CPD) framework by the Institute for Learning (IfL) appears to have exerted an impact on the respondents' perceptions of scholarly activity and research. The IfL state that for members to maintain their professional status they must undertake at least (authors emphasis) 30 hours CPD (pro rata) during the academic year, and that this CPD must be declared to the IFL by the $31^{\text {st }}$ of August each year for review (IfL, 2010). Therefore, as with their teaching, there is now an emphasis on auditing an individual's professional development. In the language of the IfL, all teachers and trainers within the FE sector are required to be members of the IfL, and given that the majority of the participants in this research taught across both $\mathrm{HE}$ and FE, they were subject to these requirements. Therefore, from their college's point of view, the respondents felt adhering to the IfL's requirements for CPD would, to an extent, be appropriate for them as HE in FE lecturers: 
"All teachers have, and this is particular to this college, have as part of their contract 30 hours CPD which can be negotiated with their line manager, and those days at time can be used on whatever is seen to be appropriate, so it could be getting work experience or it could be working with HE colleagues, it could be reading a book, it could be all sorts of varied different things." Respondent 10

Despite the enthusiasm of the respondents to engage with scholarly activity, the emphasis placed by the IfL CPD requirements was a source of considerable frustration as they felt that they were expected to participate in CPD that was geared toward FE and not $\mathrm{HE}$ :

"Well I mean as well as that you've got this whole new thing where we're supposed to be doing 30 hours a year. They believe that that will be covered within our, we get about 3 inset days a year or something. I don't consider a course on [names course] personal professional development, but they would." Respondent 9

Whilst this does not mean the respondents were not participating in scholarly activities appropriate to their HE teaching, the activities they undertook were largely self directed and carried out in their own time, and as acknowledged by Hillier (2010):

"But I do think that both the courses l've just been talking about, I chose to go on. The college has not said to me to do that and I don't think there has been any guidance from the college really at all quite honestly." Respondent 1

Given the comprehensive list of activities HEFCE (2003; 2009) cited as constituting scholarly activity, the range of activities respondents participated in appeared to be constrained by what could be achieved within a busy teaching timetable and also what activities were supported by college managers, as exemplified by Respondent 10: 
...if you call it scholarly activity, fantastic, absolutely fantastic, but if you thought about calling it research, I suppose we do support it by small research bursaries.

Indeed for specific HE related staff development and opportunities for research there was a reliance on college's validating university and/or organisations:

We have access to a range of CPD activities through the university, for example the [name of course] programme Respondent 3

Overall, as with their emerging HE practice styles, respondents indicated that there was limited recognition for the scholarly activities they participated in. Generally when they did receive recognition this tended to be localised, associated primarily with their immediate colleagues and line managers, on the whole, recognition from college management was limited. Even those respondents who were supported to carry out chosen scholarly activities commented on having to "request permission" and been "allowed to attend a conference if it was at a convenient time" i.e. did not clash with their teaching. Their experiences appear to undermine the sense of agency and autonomy they were beginning to explore in the practice styles they were employing.

The challenges the respondents highlighted regarding their engagement in scholarly activity and research are not new, they had previously been acknowledged by other studies (e.g. Anderson et al., 2002; Harwood \& Harwood, 2002; Hillier, 2010; Turner et al., 2009a; 2009b; Young, 2002). They related factors such as the absence of a research culture, limited dissemination opportunities and a lack of resources to support staff to engage in research. It is unlikely that there will be an easy resolution to these challenges however; this does not mean that HE in FE lecturers should consider plans to engage with scholarly activity and research as futile. Rather they should perhaps move away from their traditional conceptions of scholarly activities and research being associated with ivory towers of elite universities and blue skies, discovery based research, which fits with what Taylor (2008) refers to as been the golden age of academia. Instead they should consider Boyer's (1990) seminal idea 
of a 'scholarship of teaching and learning' with its four separate yet overlapping meanings: the 'scholarships' of 'discovery', 'integration', 'application' and 'teaching'.

Boyer's (1990) influential work sets the ground for an approach to research and scholarly activity within HE in FE that is based upon an awareness that the theory and practice of teaching and learning can be characterised by the same kind of rigorous professional and academic approaches to be found in other kinds of scholarship. This innovative and, in terms of the emergence of HE in FE policy implementation, prescient thinking around a 'scholarship of teaching and learning' suggests an emergent mode of praxis, the potential of which the researchers began to recognise in relation to teaching/learning and research within the $\mathrm{HE}$ in FE contexts. First of all, and in drawing upon the established theorising of action research carried by Stenhouse (1975), Carr and Kemmis (1986) and, more recently, Whitehead and McNiff (2006), the lived experience of the (HE in FE) 'teacher-asresearcher' appears to lead, in Boyer's terms, to the 'discovery' of emerging relationships between theory and research. Secondly, the researchers began to identify an 'integration' across disciplinary areas within institutions, in part due to the nascent practices of college based HE coordinators and across institutions through links established with their partner university and professional bodies. The traditional ethos of FE colleges around part-time study, work based learning and widening participation lends itself to what Boyer describes in his third 'dimension' as the 'applications' of theory and research in, for example, work based settings. Finally, and in relation to the kinds of praxis models posited in the action research based studies cited above, the research began to identify evidence of Boyer's 'teaching' practices in emergent theory practice translations. These observations of Boyer's four dimensions in action within the context of these research findings appears to offer further support for our recognition of 'communities of praxis' within the HE in FE contexts involved in the study.

The wider consideration of the applicability of Boyer's scholarship of teaching and learning that is being suggested here would allow HE in FE lecturers to contribute to the growing body of research relating to the provision of $\mathrm{HE}$ in FE, it would also allow them to once again embrace the artistry, creativity and risk that is associated with 
the traditional role of being a teacher. Ball (1995) has argued that the longstanding trend within education of setting up teaching and learning practices that resist critical and reflexive approaches not only has the effect of de-skilling education practitioners but of de-professionalising them also. A concern that has been raised by other researchers (e.g. Shain \& Gleeson, 1999; Spencerly, 2006) exploring the changing professional status of FE lecturers. Therefore through greater exploration of the scholarship of teaching and learning HE in FE lecturers can place their professional identities and practice styles at the heart of investigative inquiry. Such inquiries would help to capture and promote some of the shared communicative activities that are integral to teaching and learning. Shulman's conceptualisation of a scholarship of teaching offers an advance upon what he claims might be called 'scholarly teaching'. He suggests that by attempting to take an objective stance, by reflecting systematically on teaching practices carried out and by taking these reflections into a more public domain where findings might be peer reviewed a scholarship of teaching can be facilitated and seen to emerge (Shulman, 2004:166). We would suggest that recognition in this research of emergent HE in FE 'communities of praxis' appears to resonate with the form of theorising that Shulman is offering here.

\section{Conclusion - The Emergence of Communities of Praxis?}

We are aware that in beginning and carrying out this research we were entering a highly contested and generally under theorised terrain of practice and investigation. The anticipated post Dearing confluence of vocationalism and academia appears to be haltingly emergent and the ongoing tides of policy initiation and implementation make the coming together of HE and FE in helping to bring this about persistently problematic. However, we would claim that this research does suggest that the potential for HE teaching and learning practices to be carried out within the setting of FE institutions is possible. In, first of all, drawing upon the experiential learning qualities to be found in early reflective practice and action research approaches and then by linking these to the 'scholarship' theories of Boyer (1990), Shulman (2004) and others we would argue that this research has made it possible to postulate possible HE in FE practices that are both emergent and future oriented. So, whilst the research has identified areas where difficulties are experienced and resistances felt, in reaching this conclusion it has become possible to argue that through the 
recognition and facilitation of what we refer to as 'communities of praxis there is a way forward for HE in FE to meld together in the way in which Parry's 'furtherhigher' conflation suggests.

\section{References}

Ainley, P. 1994 Degrees of Difference: Higher Education in the 1990s. London: Lawrence \& Wishart Limited.

Anderson, G., Bolton, S. and Whalberg, M. 2003. Reflections and experiences of Further Education research in practice. Journal of Vocational Education \& Training 55 , no. $4,499-516$.

Ball, S. 1995. Intellectuals or Technicians? The Urgent Role of Theory in Educational Studies British Journal of Educational Studies 43, no.3: 255-271.

Bathmaker, A.M., Brooks, G., Parry, G. and Smith, D. 2008. Dual-sector further and higher education: policies, organisations and students in transition. Research Papers in Education 23, no. 2 125-137.

Bourdieu. P. and Passeron, J. 1977. Reproduction in education, society and culture London: Sage.

Boyer, E.L. 1990. Scholarship Reconsidered: Priorities of the Professoriate. New Jersey: The Carnegie Foundation for the Advancement of Teaching.

Bryman, A. 2008. Social Research Methods. Oxford: Oxford University Press

Carr W and Kemmis S 1986. Becoming critical: education, knowledge and action research London Falmer

Child, S. 2009. Differing relationships to research in Higher Education and Further Education in the UK: a reflective account from a practitioner perspective. Research in Post Compulsory Education 14, no.3 333-343. 
Clegg, S. 2008. Academic identities under threat. British Education Research Journal 34, no.3: 329-346.

Cunningham, J. and Doncaster, K. 2002. Developing a research culture in the Further Education sector: a case study of a work-based approach to staff development. Journal of Further and Higher Education 26, no.1 53-60.

Day, C., Kington, A., Stobart, G. and Sammons, P. 2006. The personal and professional selves of teacher: stable and unstable identities. British Education Research Journal 32, no. 4 601-616.

DfES. 2003. The Future of Higher Education. London: HMSO.

Ecclestone, K. 1999. Care or control? Defining learners' need for lifelong learning. British Jounrnal of Education Studies 47, no.4 332-347.

Elton, L. 2001. Research and teaching: conditions for a positive link (1). Teaching in Higher Education 6, no.1 43-56.

Foucault, M. 1980. Power/Knowledge; Selected Interviews and Other Writings 1972 - 1977, Brighton: Harvester Wheatsheaf

Freire, P. 1972. Pedagogy of the Oppressed. London: Penguin Books Ltd.

Glaser, B.G. and Strauss, A.L. 1967. The discovery of grounded theory: strategies for qualitative research. Chicago: Weidenfeld and Nicolson.

Harwood, J. and Harwood, D. 2004. Delivering HE in FE: perceptions of staff in five southwest colleges. Journal of Further and Higher Education 28, no.2 153-164.

Healey, M. 2005. Linking research and teaching: exploring disciplinary spaces and the role of inquiry-based learning. In: R, Barnett (ed.), Reshaping the University: New Relationships between Research, Scholarship and Teaching: 67-78. London: McGraw Hill / Open University Press. 
HEFCE. 2000. Foundation Degree Prospectus. Bristol: HEFCE.

HEFCE. 2003. Supporting higher education in further education colleges: policy, practice and prospects. Report 03/16. Bristol: HEFCE.

HEFCE. 2009. Supporting higher education in further education colleges. Policy, practice and prospects. Bristol: HEFCE.

Hillier, Y. 2010. Critical practitioners, developing researchers: the story of practitioner research in the lifelong learning sector. Journal of Vocational Education \& Training 10, no.1 89-101.

Humphreys, M. and Hoque, K. 2007. Have the lecturers lost their voice? Involvement and participation in the devolved Further Education Sector. International Journal of Human Resource Management 18, no.7 1199-1213.

IfL. 2010. Your Continuing Professional Development. www.ifl.ac.uk.

Lave, J. and Wenger, E. 1991. Situated learning: legitimate peripheral participation New York: Cambridge Press.

NICHE. 1997. Higher education in the learning society. Main report, London, HMSO. Nichols, G. 2005. New lecturers' constructions of learning, teaching and research. Studies in Higher Education 30, no.5 611-625.

Nixon, J. 1996. Professional identity and the restructuring of Higher Education. Studies in Higher Education 21, no.1: 5-16.

Parry, G. 2009. Higher Education, Further Education and the English Experiment. Higher Education Quarterly 63, no.4 322-342. 
Parry, G. 2005. HE in the learning and skills sector: England. In J. Gallacher \& M. Osborne (eds.), A contested landscape: international perspectives on diversity in mass higher education: 63-92. Leicester: NIACE.

Parry, G. and Thompson, A. 2002. Closer by Degrees: the past, present and future of Higher Education in Further Education Colleges. London: LSDA.

Schön, D. 1987. Educating the Reflective Practitioner. San Francisco: Jossey Bass.

Scott, P. 2009. On the margins or moving into the mainstream? Higher Education in Further Education in England. Higher Education Quarterly 63, no.4 402-418.

Shain, F. and Gleeson, D. 1999. Under new management: changing conceptions of teacher professionalism and policy in the further education sector. Journal of Educational Policy 14, no.4: 445-462.

Shulman, L. 2004. Teaching as a community practice: essays on higher education. San Fransisco: Jossey-Bass.

Spencerley, L. 2006. Smoke and mirrors: an examination of the concept of professionalism with the Further Education Sector. Research in Post Compulsory Education 11, no. 3 289-302.

Stanton, G. 2009. A view from with the English Further Education Sector on the provision of Higher Education: issues of verticality and agency. Higher Education Quarterly 63, no.4 419-433.

Stenhouse, L. 1975. An introduction to curriculum research and development London Heinemann

Taylor, P. 2008. Being an academic today. In Changing Identities in Higher Education: voicing perspectives, ed. R Barnett and R DiNapoli, 27-39. London: Routledge. 
Turner, R., McKenzie, L.M., McDermott, A.P. and Stone. M.A.H. (2009a). Emerging HE Cultures: perspectives from CETL Award Holders in a partner college network. Journal of Further and Higher Education 33, no.3, 255-263.

Turner, R., McKenzie, L. and Stone, M. 2009b. 'Square peg - round hole': the emerging professional identities of $\mathrm{HE}$ in FE lecturers working in a partner college network in south-west England. Research in Post-Compulsory Education 14, no. 4 355-368

Whitehead $\mathrm{J}$ and McNiff $\mathrm{J}$ 2006. Action research, living theory London Sage

Young, P. 2002. Scholarship is the word that dare not speak its name. Lecturers' experiences of teaching on a higher education programme in a further education college. Journal of Further and Higher Education, 26, no.3 273-86. 